\title{
Atmospheric waves as Earthquake precursive tools in Lithospheric Tropospheric
} Ionospheric coupling dynamics

M.Devi $^{1,2}$, A.K. Barbara ${ }^{2}$, S.Patgiri ${ }^{1,2}$ A. Depueva ${ }^{3}$, A. Medhi ${ }^{2}$, K Oyama $^{4}$, V Depueve ${ }^{3}$ and Ya Yu Ruzhin $^{3}$

${ }^{1}$ Dept. of Physics, Gauhati University, Guwahati-14, India

${ }^{2}$ ST Radar Centre, Gauhati University, Guwahati-14, India

${ }^{3}$ Pushkov Institute of Terrestrial Magnetism, Ionosphere, and Radio Wave Propagation, Russian

Academy of Sciences (IZMIRAN), Moscow, Troitsk, 108840 Russia

${ }^{4}$ International Center for Space Weather Study and Education, Kyushu University, Fukuoka, Japan

\begin{abstract}
:
Amongst a number of precursory features in the atmosphere observed through Electro Magnetic (EM) techniques, the variabilites of the lower and upper atmosphere are considered to have yielded reasonably satisfactory results, though reliabilities as nowcasting are yet to be ascertained. Of recent interest in such studies are the waves and undulations possibly generated by Earth Quake (EQ) preparatory processes. Even with number of studies taken up in relevance to this issue, more inputs are necessary to make comprehensive views of generation process of such waves with special reference to an impending EQ . Under this background the paper presents analysis of Total Electron Content (TEC) and Scintillation from GPS observation at Guwahati in identifying generation of waves prior to an earthquake for realizing Lithosphere -Troposphere -Ionosphere (LTI) coupling dynamical status caused by EQ preparatory processes. The anomalous appearance of satellites from beyond the normal Line of Sight (LOS) prior to an EQ and their positions analyzed through respective azimuthal status ( with PRN in each case) are finally utilized in identifying the sources associated with generation of waves. The role of EQ induced tropospheric parameters as Radio Refractive Index (RRI) and Effective Earth Radius are brought in to the ambit of discussions.
\end{abstract}

Key words ; Waves, Earthquake, TEC, Scintillations, Satellites- PRN , RRI

\section{Introduction :}

The processes of growth and development of wave-structures in the atmosphere have significant importance because such waves could cause a redistribution of their momentum and energy, thereby leading to modification in the atmospheric physical and dynamical processes footprints that could be a precursor to an EQ. Therefore, generation and propagation of waves and TIDs in the atmosphere be it in 
the neutral or in ionized stages, have been a subject of study by scientists all throughout the globe and extensive reports on association of such structures with ionospheric perturbations and phenomena like spread F, bubbles \& plumes and in the neutral atmosphere [Fritis and Rastogi 1985 ; Fritis et al., 1988 ; Zettergren and Snively 2015] are well received. The waves in the non ionized medium are mainly the result of restoring forces when a fluid parcel is displaced from equilibrium state caused by natural or anthropogenic sources. Depending on the type of restoring forces whetrer of be gravity, rotation or electromagnetism forces, the waves attain their a distinctive special characters [Devi et al., 2007; 2017]. The restoring force if gravity, these waves are termed as gravity waves, the type that we would be interested here. Such waves no doubt have significant modulating effects on ionospheric parameters and reports are available associating development of such waves with earthquake induced processes along with possible utilization of their signature in understanding coupling dynamics of lower-upper atmosphere [Hayakawa and Molchanov, 2002 ; Mareev et al., 2002; Hegai et al ., 2006 Laštovička 2006 ; Horie et al., 2007; Muto et al., 2009; Hayakawaet al., 2011; Yiğit and Medve dev 2015].

But, the EQ- induced effects on the ionosphere are inherently complex in nature, because of influences of solar geomagnetic ambience even on normal days and therefore extraction of undulating features on EQ time TEC becomes an involved process . Modifications forced into the ionosphere by an EQ, depend also on relative position between epicentre-observing station, mainly in terms of geomagnetic latitudes [Devi et al., 2001; 2004; 2010 a; 2011a, Devi et al ., 2012a; 2012 b; 2015 ; Ryu et al., 2016; Oyama et al., 2019]. The situation becomes more involved at low latitude, when Appleton anomaly itself provides additional coupling dynamics through ExB drift processes [Depueva \& Rotanova 2001; Devi et al ., 2004; Sun et al., 2011] . Further, it is also observed that [ Devi et al., 2004; Depueva et al., 2007], earthquake time changes in TEC occur not only during noon period but also in post noon and after sunset hours, suggesting that it is important to look for seismic features in TEC for the entire day. Under this background the entire profile will be examined for the case studies taken up here in identifying growth of wave structures by EQ preparatory processes.

\subsection{Analysis and results:}

\subsection{Wave structure at the near earth environment prior to $E Q$}

In one of our earlier observations we have shown signatures of slopping structures [Devi et al., 2007 ; Devi et al .,2017] in sodar echogram, a reproduction of which is presented in Figure 1. These structures 
appeared 5/6 hours prior to the occurrence of the earthquake of $18^{\text {th }}$ November, 1996 with $\mathrm{M}>5.5$ at a location near to the sodar site at GU $\left(26^{\circ} \mathrm{N}, 92^{\circ} \mathrm{E}\right)$. The source of generation of these waves is shown to be at troposphere by Devi et al,, [2017]. However, the sources on growth and generation of such structures are still a debatable issue. While a section of observers support the sources to be at lower atmosphere [Pulinets and Boyarchuk, 2004;Lizunov and Hayakawa, 2004; Hayakawa et al., 2011] , through excitation of such waves by EQ time emission of radon, water and then move up generating perturbation in the ionosphere, there are also reports associating the wave-source at the upper atmosphere as by Yang, et al., [2019] who had detected abnormal gravity wave activity in the stratosphere prior to the 2016 Kumamoto earthquakes. There are also accumulated reports in support of Lithosphre-Atmosphere-Ionosphere coupling through Atmospheric Oscillation in the atmosphere [Hayakawa, 2011; Rozhnoi et al., 2007; Lizunov and Hayakawa, 2004]. But still, origin of the waves in the atmosphere is a debatable issue more so in EQ ambiances and here in this paper a few case studies are presented to examine possible development of EQ induced waves with the aims to identifying their origin and their possible role in LTI coupling.

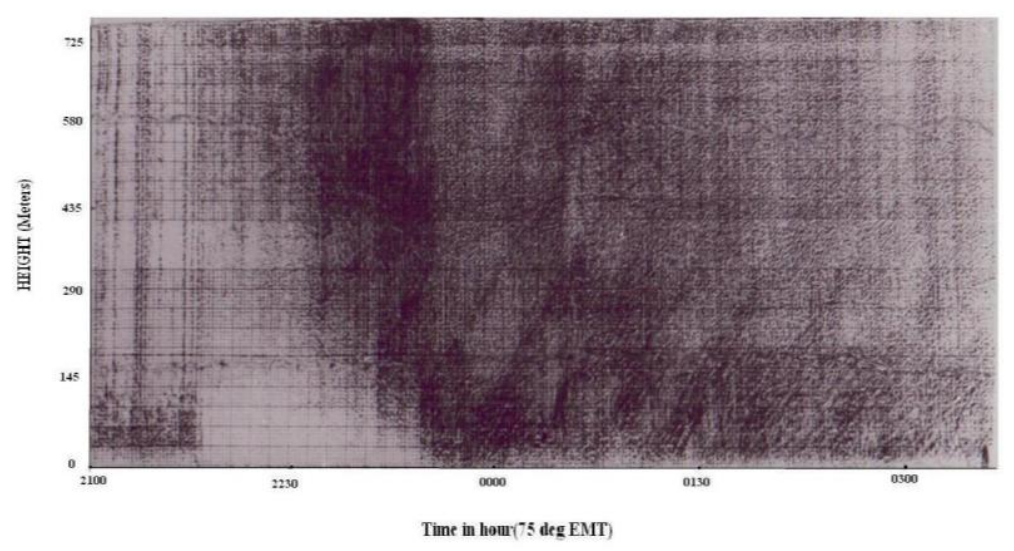

Figure 1: Compression and rarefaction of the wave in the atmosphere leading to slopping structures are seen prior to an earthquake of M.>5.5 occurred near to the observing site of the Sodar.[ Devi et al., 2007; 2017 ]

\subsection{TEC and EQ induced TIDs :}

\subsubsection{Observations}

The basic data sources taken in this study are GPS derived TEC and scintillation at Guwahati ( $26^{\circ} \mathrm{N}$, $92^{\circ} \mathrm{E}$ ) and Global TEC profiles . The TEC \& scintillation data during a few earthquake cases considered here, are analyzed for identifying EQ time wave structures and then to utilize the necessary inputs from 
GPS derived parameters in detection of possible source of the waves. Finally to understand the role of EQ time waves in Lithosprheric- tropospheric -ionospheric dynamical coupling.

The approaches for identification of any perturbed feature from TEC profiles, though may vary, it is a necessity that TEC data to be processed and filtered so that its Quiet-(Q) day excursions do not obliterate the seismic-induced TEC pattern. Thus we adopt the very approaches as discussed in our earlier papers [Devi et al.,2001; Devi et al ., 2011a] by taking Sd limit of Q-day TEC excursion. Further, as changes in TEC (mainly in any disturbed environmen), do occur not only in noon hours but all along the day [Devi et al., 2004; 2011a], profile shape is also an important parameter in study of the types aimed here. For this purpose we define a parameter called Profile factor (P-factor) [ Devi et al., 2011a; 2011b] : it is the period of the profile that maintains $70 \%$ of noon time TEC peak. A large number of TEC profiles are then examined for each day of a month for defining a Q-day P-factor and deviation of this parameter for individual day will be a measure of anomaly..

\section{Case I :Earthquake of August 12, 2009, Epicenter at $24.34^{\circ} \mathrm{N}$ and $94.79^{\circ} \mathrm{E}$ and $\mathrm{M}=5.5$ )}

The case considered here is for an EQ that occurred on August 12, 2009 near India -Myanmar border (Figure 2). The TEC features obtained by GPS at Guwahati covering a few days prior to the EQ to the day of the event, are presented in Figure 3. As mentioned earlier, one can identify from the figure that modulations on TEC profiles are present not only during noon period but also in post noon \& after sunset hours and significantly the wave structures are seen to be more intense during decay period ( as marked within a box) as displayed in Figure 3. In Figure 4 , the decay profiles of TEC are therefore presented for a nomal day ( day-5, Figure 4a) and for day-1, one day prior to the EQ ( Figure 4b). The normal decay pattern (Fig, 4a, 5 days prior to the EQ) is observed to be modulated by $2 / 3$ hrs periodic component as the day approaches to the seismic event (Figure 4b) and the waves disappear just after the EQ event (Figure 5). 


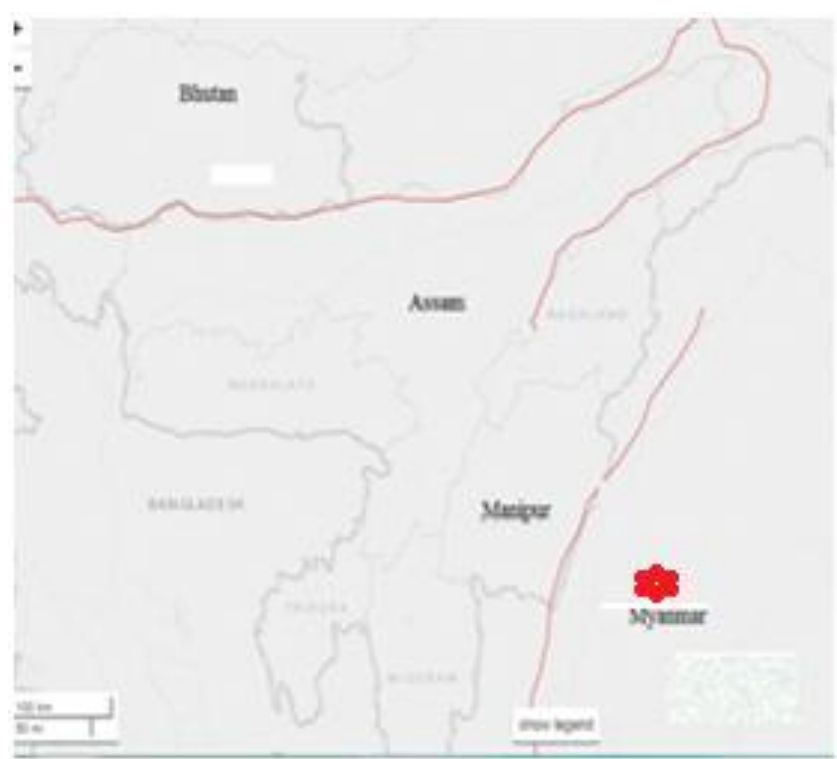

Figure 2: The EQ epicenter (marked by red star) in India -Myanmar Border . Note the fault position, (the red line ) to the east near the epicenter.

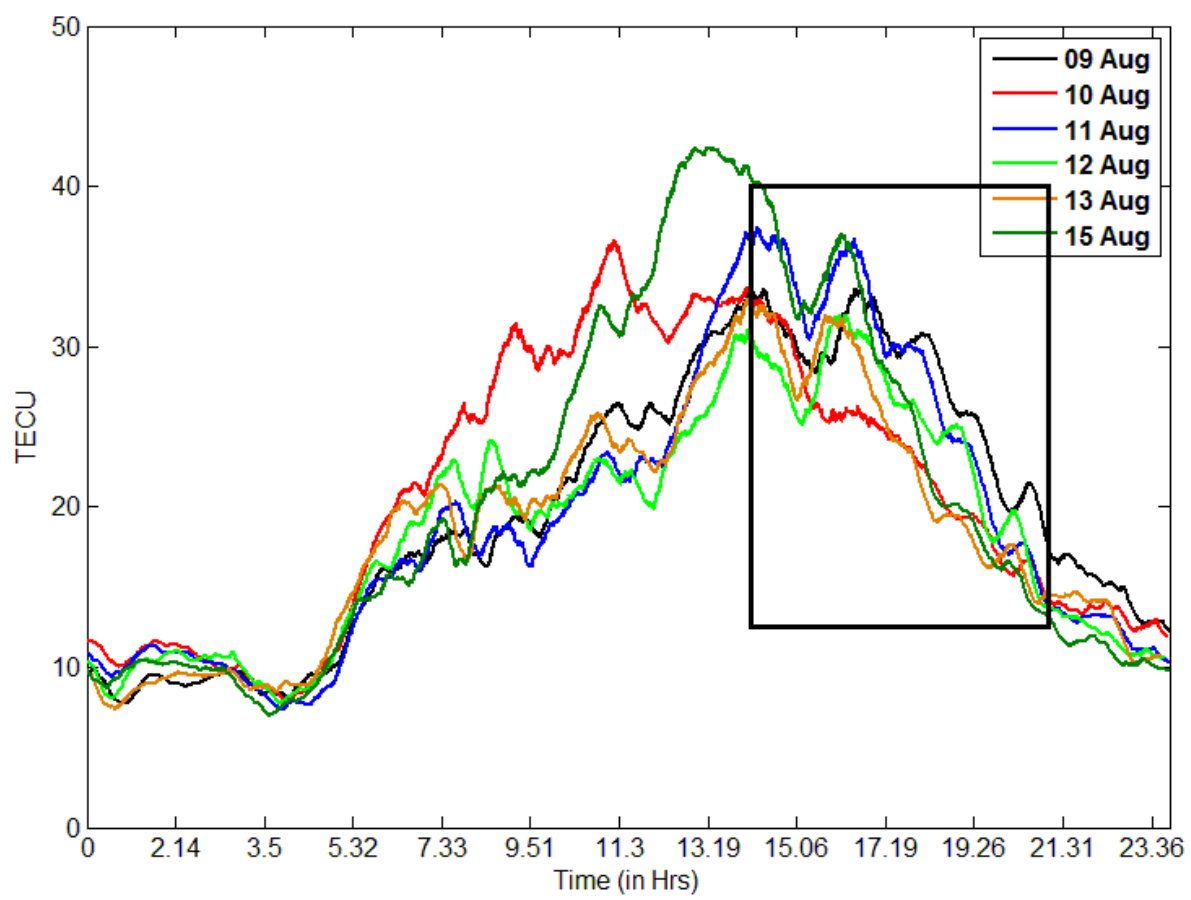

Figure 3 : GPS derived TEC diurnal profiles over Guwahati prior to, during and after the August Earthquake. The wave staructure during decay period is enclosed bya rectangle 


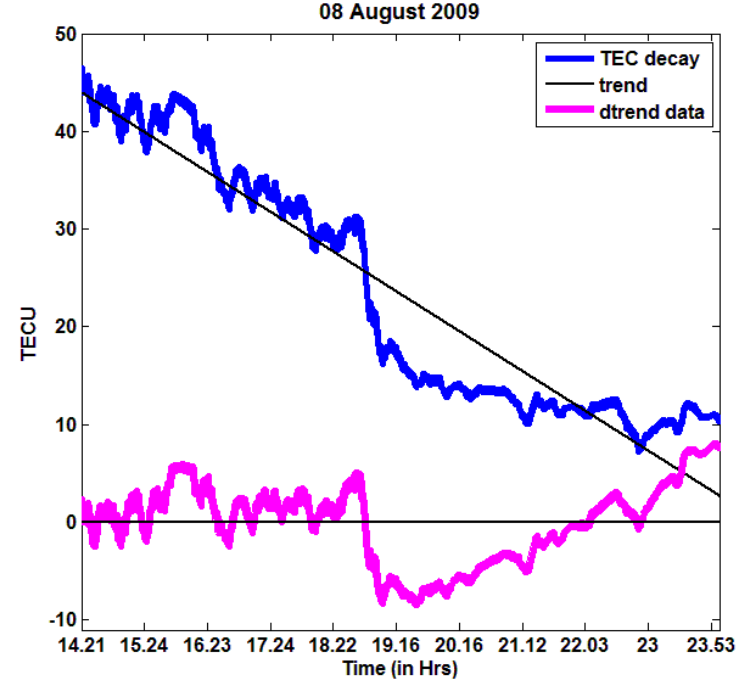

(a)
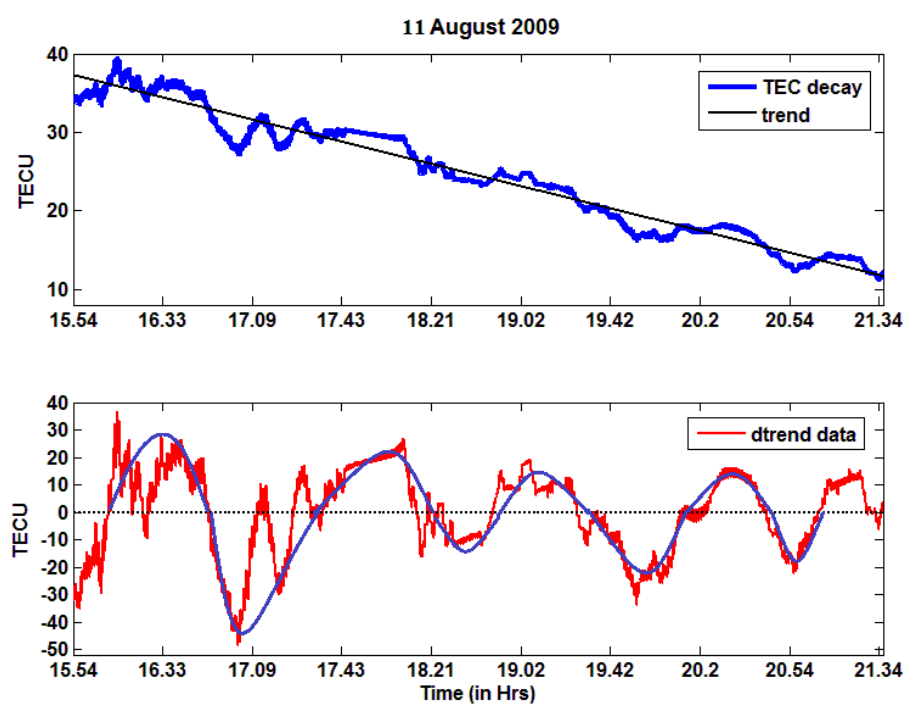

(b)

Figure 4: TEC decay rate and de-trended profiles (a) normal situation i.e., 5-days prior to the EQ and (b) one day prior to the EQ . Note presence of wave structures in (b).
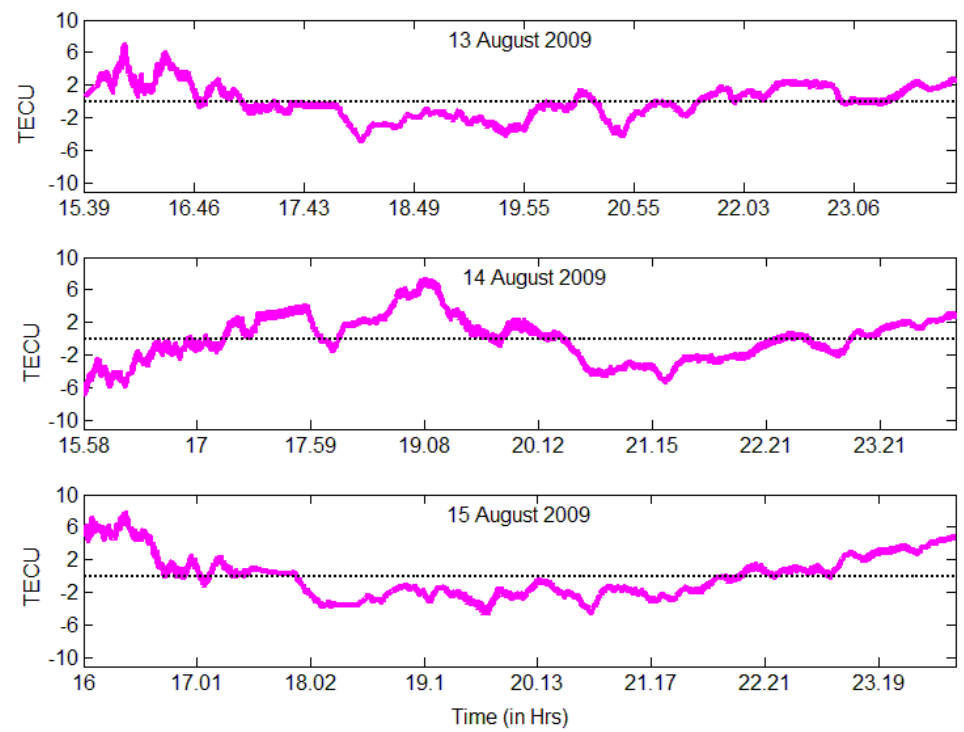

Figure 5 : Wave structures disappeared after the August 12,2009 EQ 


\section{Case II: EQ of 21.9.2009 in Bhutan with epicenter at $27.32^{\circ} \mathrm{N}, 91.42^{\circ} \mathrm{E}$}

The 2009 Bhutan earthquake with magnitude $M=6.1$ that occurred at 08:53 hrs UT, on September 21, 2009 , is another case taken up here. The epicenter was at $27.32^{\circ} \mathrm{N}, 91.42^{\circ} \mathrm{E}, 180$ kilometers (radius $=445.85 \mathrm{~km}$ ) east of the capital Thimphu. The lithospheric structure of the epicenter area and the perspective positions of Bhutan \& Guwahati are presented in Figure 6.

The TEC noon peak values obtained from GPS observations at GU along with the Q-Day excursion limit of Standard Deviation (SD) of TEC for the month of September 2009 are presented in Figure 7, with the EQ events of this month as marked by stars. The two horizontal lines indicate the upper and lower SD limits from the Q-Day mean value of the TEC noon peaks. Our precursor day definition [ Devi et al., 2011a] that goes as : " the day when TEC peak shows decline after exceeding the maximum excursion bar of SD limit of Q-day TEC (thick lines)" , identifies the $21^{\text {st }}$ September as possible EQ day marked in the figure and also the actual day of the event. Similar conclusion is also drawn from the Pfactor profile of Figure $7 \mathrm{~b}$.

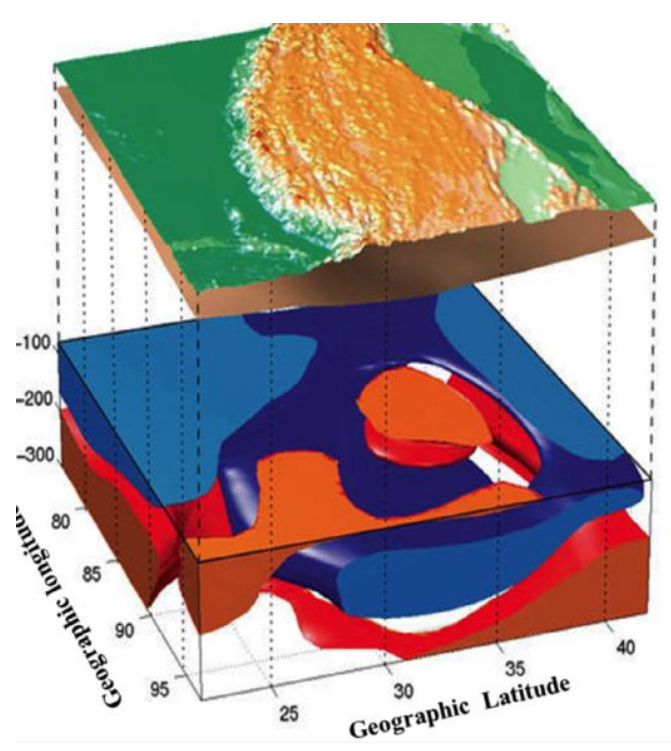

(a)

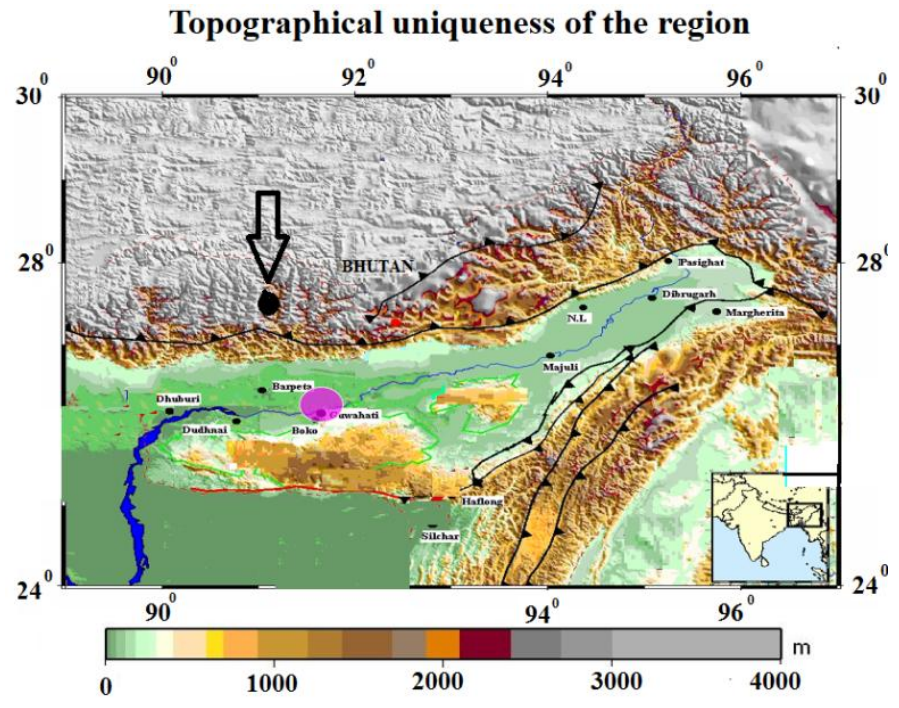

(b)

Figure 6 : (a) Lithosphere structure of Bhutan epicenter ( reproduced picture from Devi et. al., 2015) (b) Epicenter position (marked by a black errowhead) and Guwahati GPS receiver site(identified by pink dot) . Note that aurogrpahy status of the epicenter and surroundings. 


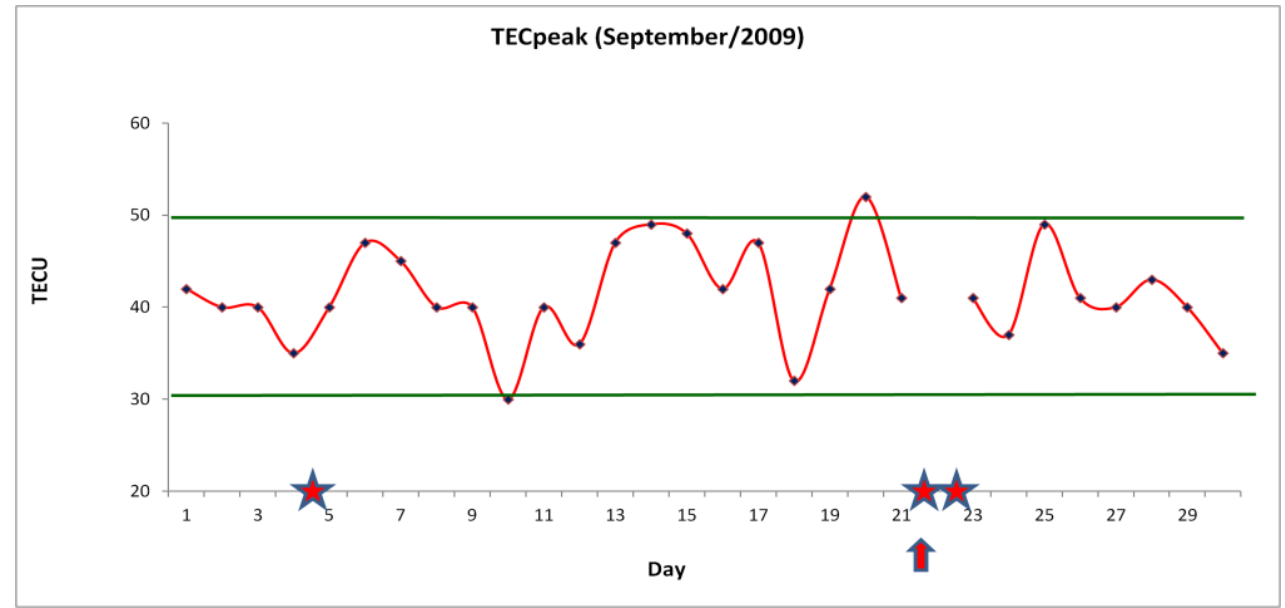

(a)

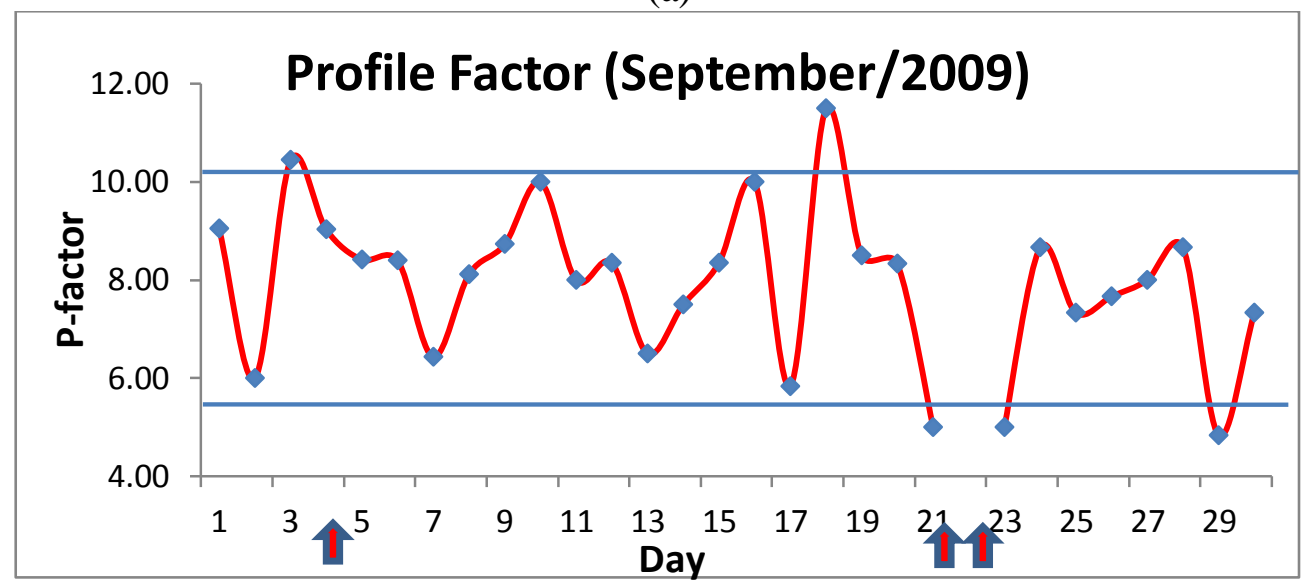

(b)

Figure7: (a) TEC noon peaks for the month of September, 2009 indicating expected EQ days (by arrow heads) and EQ events (by stars). The thick lines indicate the excursion limits of Q-day TEC fluctuations. (b) P-factor for the month of September, 2009 indicating expected EQ days (by arrow heads) and EQ events (by stars). The thick lines indicate the excursion limits of Q-day P-factor.

These analyses no doubt supports the fact that GPS 'TEC noon peak' observed at Guwahati could be adopted in identifying an impending EQ when receiver lies within the EQ preparatory processes. However one additional point that we would like to add here is that TEC noon peak may not be the sufficient input to providing the wave related information for all the atmospheric and other associated environment as discussed in the next article. 


\subsubsection{Wave structures from TEC and Scintillations :}

In the process of identifying the wave structures, we take the TEC values registered by all the satellites and not considering only the vertical satellite views alone. Thus, the satellites from anomalous positions not generally coming in to the normal field of GPS receiver view will also be accounted here in TEC calculation specially paying attention to anomalous TEC records. Figure 8 presents diurnal profile on TEC anomalous variations (TEC $>70 \mathrm{U}$ ) from all satellites received even from extreme oblique path and one can identify presence of wave structure with a periodic component of three to four hours prior to two and one day of the September 2009 EQ . It is Interesting to note from Figure 8 that relatively high scintillations occur in synchronization with the wave structure obtained in TEC (anomalous) diurnal pattern .

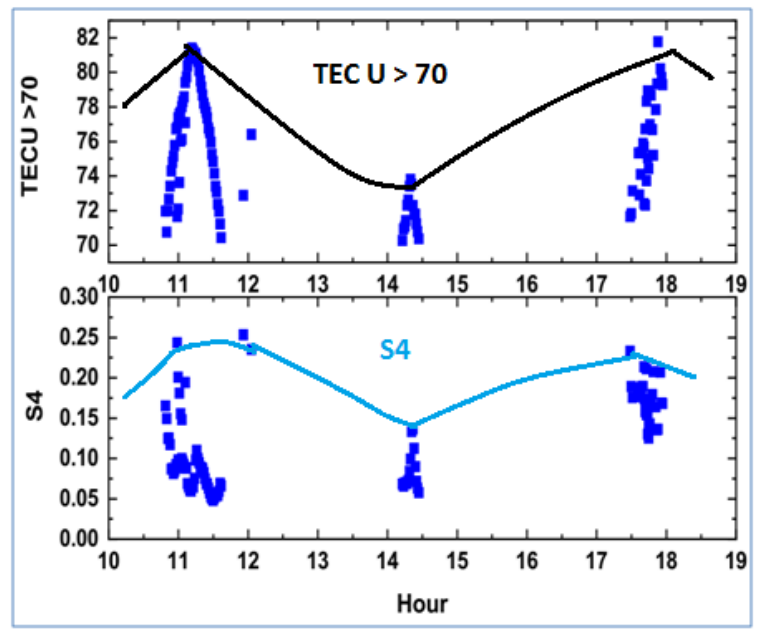

(a)
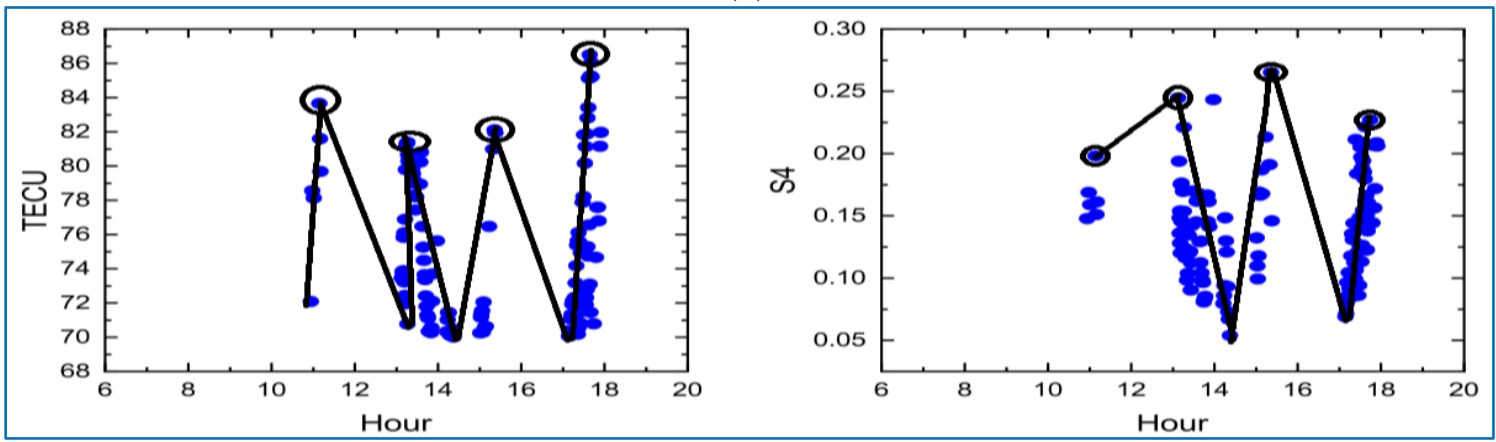

(b)

Figure 8 : Diurnal variation of anomalous TEC and scintillation S4 index on (a) Day-2 and (b) Day-1 of the EQ event of September 2009 . Note presence of wave structure on the anomalous TEC /scintillation diurnal pattern. 


\subsubsection{Association of satellite positions, anomalous TEC and Wave structures :}

To examine the satellite status registering such high electron content values, TEC profiles are passed through filters with TEC $>70$ units (anomalous), along with the respective PRN positions. The analysis presented in Figure 9 results that these wave like oscillations are observed mainly in anomalous

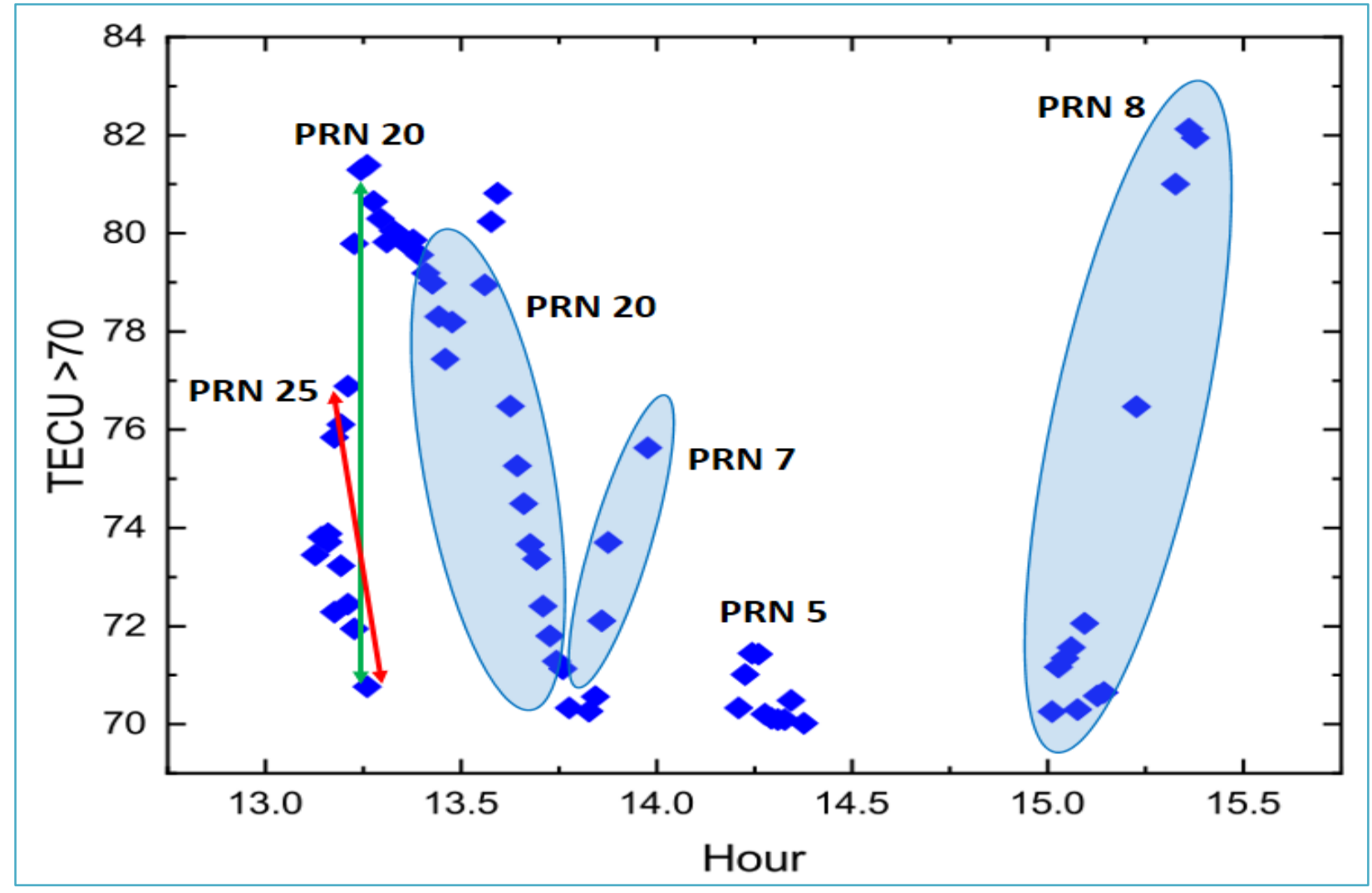

Figure 9 :A few satellites (PRN 25, PRN 20, PRN8) appearing from beyond the normal LOS path, provide abnormal Electron Content values along with wave like undulating features of Figure 8. PRNs are marked by blue ractangles.

background of TEC values, registered by only a few satellites mainly with PRN 25, PRN 20, PRN 8 (Figure 9). These satellites are coming in to the receiver view through oblique ray path and are thus from beyond the normal FOV path. The observational conclusion is that the anomalous appearance of satellites provide abnormal TEC values $>70$ TECU along with wave like undulating features ( see Figure 8). Finally, the Azimuth positions of $160^{\circ}-240^{\circ}$ associated with these special satellites ( Figure 10) when converted to respective geographical coordinate, correspond to $20^{\circ}-25^{\circ} \mathrm{N}$ latitude and $90^{0}$ longitude, 
almost coinciding with the EQ epicenter of $27.32^{\circ} \mathrm{N}, 91.42^{\circ}$ Ewhich are not generally appear in the FOV of GPS receiver .

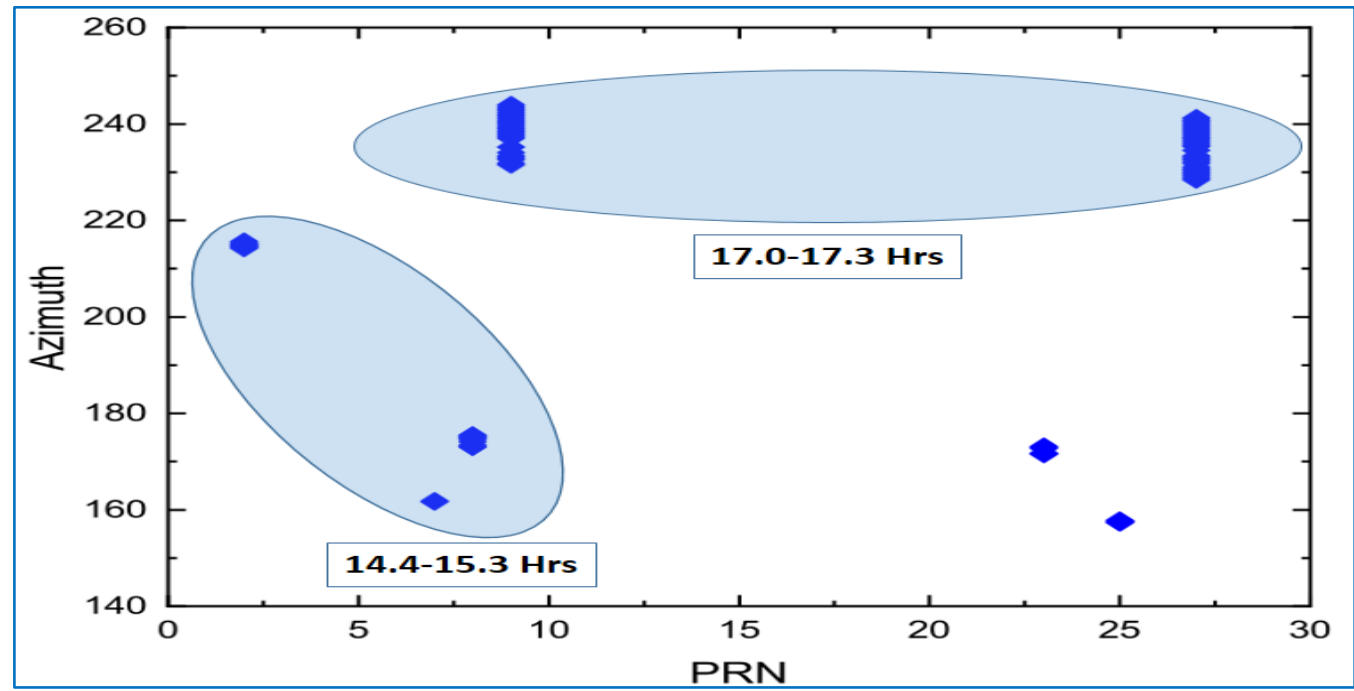

Figure 10: SatelliteAzimuth for corresponding PRN, shown by blue dots . Note azimuth $160^{\circ}-240^{\circ}$ corresponds to $20^{\circ}-25^{\circ} \mathrm{N}$ latitude and $90^{\circ}$ longitude. Corresponding periods of their appearances are also marked.

\subsection{Source of origins of waves : Discussions}

TECfeatures, VLF /VHF propagation characters are though well adopted as preludes to an impending EQ, the atmospheric waves as tool in this aspect are still a debated exercise because of the complex modes of their generation and propagation. Identification of sources of such waves are far more involved process because of possible coupling dynamics from lithosphere to magnetosphere. In this work we have associated the anomalous appearance of satellites with abnormal TEC accompanied by waves. One possible sources of anomalous appearance of satellite from beyond the normal FOV is through extension of the line of sight path by EQ modified tropospheric features specially by refractive index [ Devi et al ., 2010b; 2012a; 2012b; 2015 ]. It is well known that the Line Of Sight tropospheric propagation is controlled by the refractive index ' $n$ ' of the medium and in normal atmospheric situations when effective earth radius $k=4 / 3$, the ray curvature gives the standard field of view of line of sight propagation .But the path geometry modifies with changes of refractive index, and propagation of signal beyond the normal view of the trans-receiver link is made possible. The change of $\mathrm{n}$ being small, 
a factor called RRI is introduced denoted by a factor $\mathrm{N}=(\mathrm{n}-1) \times 10^{6}$. The RRI depends on the tropospheric variability like temperature $(\mathrm{T})$, water vapor pressure $(\mathrm{e})$ and atmospheric pressure $(\mathrm{P})$ by a relation (1) and effective earth radius ' $\mathrm{k}$ ' (ER) factor is expressed by equation (2), which is controlled by the RRI gradient .

$\mathrm{N}=(\mathrm{n}-1) \times 106=(77.6 \mathrm{P}) / \mathrm{T}+(375000 \mathrm{e}) / \mathrm{T}^{2}$

$\mathrm{k}=\mathrm{ae} / \mathrm{a}=1 /(1+\mathrm{a} \mathrm{dN} / \mathrm{d} h)$

Thus a change in RRI/km from the normal-value will increase or decrease the FOV . As an example a modification in RRI by $12 \%$ will modify the effective ER to $8000 \mathrm{~km}$ [Devi et al., 2019], when it is possible to see a satellites from beyond the normal FOV range oblique ray traversing in oblique path through the troposphere. The presence of waves registered only by these satellite in the background of anomalous TEC could thus be identified as of tropospheric origin, in support to observation of gravity waves by SODAR setup of Gauhati. The modulation detected in TEC may be the result of propagation of waves to the upper atmosphere initiating the LTI coupling link. Reports was also received on internal gravity waves (IGW) of extremely small amplitude due to the ground motion during an EQ, which interact with planetary scales waves below $10 \mathrm{~km}$, and areamplified [ Oyama et al., 2016] . The amplified IGW propagates to the dynamo region, modifies the wind system, or conductivity, which modifies the electric field.

Our recent observations on TEC modifications during strong April 2014 EQ of Solomom island [Devi et al ., 2019] lying within the fault zone and equatorial anomaly belt indicate more than 50\% enhancement in density prior to the EQ event and these anomalous density are found to be registered by Satellites which are not visible during normal days and came in to the LOS of GPS receiver at GU, prior to EQ. These phenomena are tried to explain through modification imposed on troposphere by EQ preparatory processes. These explanations go in parallel to the two EQ cases that we have presented here, but more complex dynamics seems to involve here because of complex topography of the epicenter and also that the epicenters lie near/ along the fault line. In this aspects we can refer to the hypothesis where water, radon, gas emanation etc., before an EQ could excite the AGW oscillations and those AGWs propagate upwards and obliquely and result in the lower ionospheric perturbations [Lizunov and Hayakawa, 2004] It is our future plan work to examine role of radon or gas emission through fault line in generation of waves by earthquake preparatory processes and their consequent propagation to ionospheric height. 


\section{Acknowledgments:}

The authors M. Devi, A.K. Barbara, V. Depuev, A. Depueva, and Yu. Ruzhin acknowledge with thanks the financial support received from the DST, India and RFBR, Russia through Grant no. 17-55-45094 a_IND., for conducting this work under the project -"Lower atmospheric forcing leading to modifications in the upper atmosphere ". Further, M. Devi and K I Oyama express their deep acknowledgment to the Mitsubishi Foundation for providing research Fund (ID: 26113) in carrying out part of the work of the paper.

\section{Reference:}

Depueva, A. H. and Rotanova, N. M. Low-Latitude Ionospheric Disturbances Associated with Earthquakes.Annals of Geophysics, Vol. 44, No. 2,221-228, 2001.

Depueva, A.Kh.,Mikhailov, A.V., Devi, M., Barbara, A.K. Spatial and time variations in critical frequencies of the ionospheric $\mathrm{F}$ region above the zone of equatorial earthquake preparation. Geomagn. Aeron. 47 (1), 129-133,https://doi.org/10.1134/S0016793207010197,2007.

Devi, M., Barman, M.K., Barbara, A.K.,Depueva, A.H. Total electron content near anomaly crest as precursor of earthquake.Indian Journal of Radio \& Space Phyics, 30,209-213,2001.

Devi, M., Barbara, A.K.,Depueva, A.H. Association of total electron content and foF2 variations with earthquake events at the anomaly crest region. Annals of Geophysics, 47, 83-91,2004.

Devi, M., A. K. Barbara, Yu. Ya. Ruzhin and A. Depueva. Beyond the Horizon Propagation of VHF Signals: Atmospheric Features and Earthquake," Electronic Journal, Investigated in Russia, Vol. 129e, No. 39, 2007, 1331-1340,2007.

Devi M, Barbara AK, Kashyap P,Depueva A, Ruzhin YY, Depuev V. Earthquake time low latitude total electron content (TEC) variations and model based pattern: identification of earthquake induced atmospheric dynamics. AdvGeosci 28, 69-84,2010a.

Devi, M., A.K. Barbara, A.H. Depueva, Y.Y. Ruzhin and V. Depuev. Anomalous Total Electron Content (TEC) and atmospheric refractivity prior to strong China earthquake of May 2008, Int. J. Remote Sens., 3, 3589-3599,2010b.

Devi, M., A.K. Barbara, P. Kashyap, A. Depueva, Ya. Yu Ruzhin, Depuev,V.Earthquake time low latitude Total electron Content (TEC) variations and model based pattern: Identification of Earthquake Induced Atmospheric Dynamics Advances of Geosciences 20,69-84,2011a. 
Devi, M., A. J. D. Sarma, S. Kalita A.K. Barbara,Depueva,A. Adoptive techniques on extraction of pre-seismic parameters on Total Electron Content (TEC) at anomaly crest stations using GPS data. Geomatics, Natural Hazards and Risk, DOI:10.1080/19475705.2011.595831,2011b.

Devi M. A. K. Barbara Ya. Yu. Ruzhin, M. Hayakawa. Over-the-Horizon Anomalous VHF Propagation and Earthquake Precursors SurvGeophys. An International Review Journal Covering the Entire Field of Geosciences and Related Areas DOI 10.1007/s10712-012-9185-z,2012a.

Devi, M., and A.K. Barbara. Total Electron Content and Anomalous Appearance of GPS Satellites as Pointers to Epicenter Identification of Major Japan Earthquake of 2011. Positioning, 3, 7-12,2012b.

Devi M., A. Medhi, A.K. Barbara, A. Depueva, Y. Ruzhin.Orographic role in anomalous VHF propagation on the background of impending earthquakes. ANNALS OF GEOPHYSICS, Vol.58, No. 3, A0333; doi:10.4401/ag-6716, 2015.

Devi, M., Patgiri, S., Barbara, A. K., Depueva V. Note: Atmospheric waves as earthquake precursors seen in SODAR echogram. International Journal of Electronics and Applied Research (IJEAR); Vol. 4, No.1, ISSN2395-0064,https://doi.org/10.33665/IJEAR.2017.v04i01.003, July 2017.

Devi, M A.K. Barbara ,S.Patgiri, A. Depueva , K Oyama, V Depueve and Ya Yu Ruzhin. Perturbation Features imprinted on Ionosphere by successive clusters of Strong earthquakes: Role of atmospheric coupling dynamics. Geomagnetism and Geoelectric, No 8, 2019 (in press).

Fritis D C and Rastogi P. K . Convective and dynamical instabilities due to gravity wave motion in the lower and middle atmosphere : Theory and observations. Radio Sci., 20, 1247-1277, 1985.

Fritis D C, Tsuda T, Sato T, Fukao S and Kato S. Observational evidence of a saturated gravity wave spectrum in the troposphere and lower stratosphere. J. Atmos. Sci., 45, 1741-1759, 1988.

Hayakawa, M., and O.A. Molchanov, eds. Seismo electromagnetics, lithosphere-atmosphere-ionosphere coupling. Terra Scientific Publishing Co., Tokyo,2002.

Hayakawa M, Kasahara Y, Nakamura T, Hobara Y, Rozhnoi A, Solovieva M, Molchanov OA, Korepanov V. Atmospheric gravity waves as a possible candidate for seismoionosphericperturbations.JAtmosElectr 31:129-140,2011.

Hegai, V. V., V. P. Kim, J. Y. Liu. The ionosphere effect of atmospheric gravity waves excited prior to strong earthquake.Adv. Space Res., 37, 653 - 659, 2006.

Horie T, Yamauchi T, Yoshida M, Hayakawa M. The wavelike structures of ionospheric perturbation associated with Sumatra earthquake of 26 December 2004, as revealed from VLF observation in Japan of NWC signals. J Atmos Solar-TerrPhys, 69:1021-1028,2007. 
Lizunov,G. V.,Hayakawa,M. Atmospheric Gravity Waves and their Role in the Lithosphere-troposphereionosphere Interaction. IEEJ Transactions on Fundamentals and Materials Vol.124 No.12,1109-1120, DOI: 10.1541/ieejfms.124.1109,January 2004.

Laštovička J Forcing of the ionosphere by waves from below. J Atmos Sol TerrPhys 68:479-497,2006.

Mareev E.A., Iudin D.I., Molchanov O.A. Mosaic source of internal gravity waves associated with seismic activity. In: M. Hayakawa and D. Molchanov (eds.), Seismo-Electromagnetics (LithosphereAtmosphere-Ionosphere Coupling), Tokyo: Terra Scientific Publishing Company, 335-342.29-140,2002.

Muto, F. Y. Kasahara, Y. Hobara, M. Hayakawa, A. Rozhnoi, M. Solovieva, and O. A. Molchanov. Further study on the role of atmospheric gravity waves on the seismo-ionospheric perturbations as detected by sub ionospheric VLF/LF propagation. Nat. Hazards Earth Sys. Sci., 9, 1111- 1118, 2009.

Oyama , K I, Liu H, Devi M, Liu J Y, Ryu K and Chen C H. Statistical Study on Ionosphere disturbance before large earthquake. Report on Ionospheric Precursor Study Task group , Mitsubishi Foundation (ID: 26113), 1-104,2016.

Oyama, K. -I. C. H. Chen, L. Bankov,' D. Minakshi, K. Ryu,J. Y. Liu, and H. Liu. Precursor effect of March 112011 off the coast of Tohoku earthquake on high and low latitude ionospheres and its possible disturbing mechanis, Adv. Space Res, 2019. (press)

Pulinets, S.A. and Boyarchuk, K.A. Ionospheric Precursors of Earthquakes. Springer, Berlin. DOI10.1007/b137616Hardcover ISBN978-3-540-20839-6,2004.

Rozhnoi, A., M. Solovieva, O. Molchanov, P. F. Biagi, and M. Hayakawa. Observation evidences of atmospheric gravity waves induced by seismic activity from analysis of sub ionospheric LF signal spectra.Nat. Hazard Earth Sci., 7, 625- 628, 2007.

Ryu, K., Oyama, K.-I., Bankov, L., Chen, C.-H., Devi, M., Liu, H., Liu, J.-Y. Precursory enhancement of EIA in the morning sector: contribution from mid-latitude large earthquakes in the north-east Asian region. Adv. Space Res, Vol.57 No.1, 268-280,https://doi.org/10.1016/j.asr.2015.08.030,2016.

Sun, Y.Y., K. -I. Oyama, J. Y. Liu, H. K. Jhuang, and C.Z.Cheng, The Neutral Temperature in the IonosphericDynamo Region and the Relation with the IonosphericDensity duringWenchuanandPingtung Earthquakes, Nat,Hazard. Earth Syst. Sci., 11, 1759- 1768,2011.

Yang, S. S., Asano, T., and Hayakawa, M. Abnormal gravity wave activity in the stratosphere prior to the 2016 Kumamoto earthquakes. J. Geophys. Res., Space Phys., 2019(in press)

Yiğit E, Medvedev A.S.Internal wave coupling processes in earth's atmosphere, Adv Space Res, Vol 55No.5, 983-1003,http://www.sciencedirect. com/science/artic, 2015.

Zettergren, M. D., and J. B. Snively, Ionospheric response to infrasonic - acoustic waves generated by natural hazard events, J. Geophys. Res., doi: 10.1002/2015SJA021116, 2015. 